\title{
Mitochondrial ND5 mutations mimicking brainstem tectal glioma
}

Figure MRI showing a periaqueductal high T2 signal on axial T2 (A) and sagittal T2 (B) and an enlargement of the tectum that mimicked tectal glioma in all 3 children (case 1, 9 years; case 2, 6 years; case 3, 7 years)

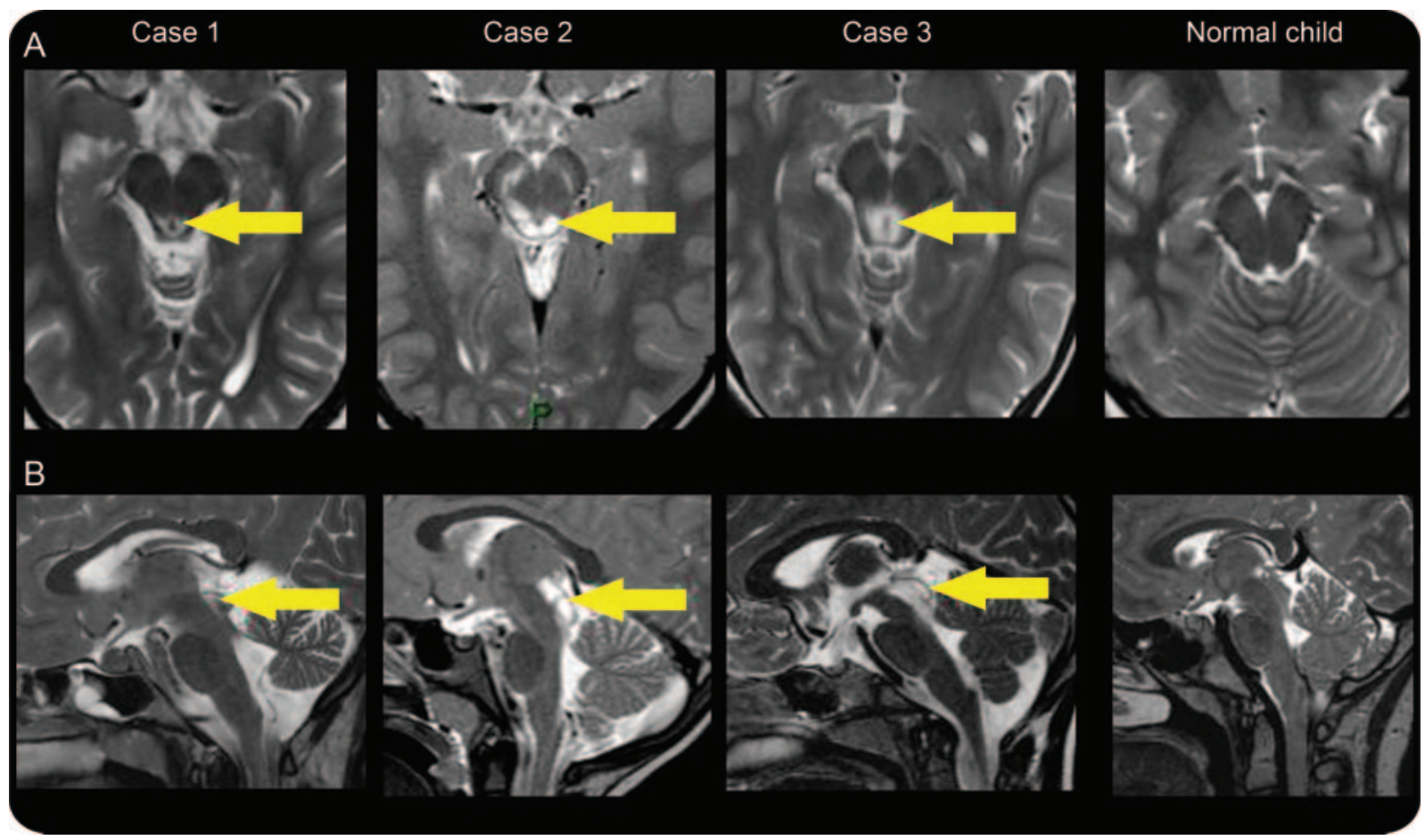

We report MRI periaqueductal T2 hypersignal suggestive of tectal glioma in 3 unrelated children with reduced vision and normal mental development (figure). Increased CSF lactate and optic atrophy in the first case suggested mitochondrial dysfunction. Muscle biopsy revealed complex I deficiency. A heteroplasmic mt-ND5 mutation was found (m.13513G $>$ A). ${ }^{1}$ The second case presented with similar clinicoradiologic features, complex I deficiency, and the same heteroplasmic mutation. The third case had visual disturbance without optic atrophy, normal muscle enzyme activities, and a heteroplasmic mt-ND5 mutation (m.13514A $>\mathrm{G}){ }^{2}{ }^{2}$ Even in absence of optic atrophy, mental retardation, or multiorgan dysfunction, the combination of visual disturbance and periaqueductal T2 hypersignal should prompt the search for mitochondrial DNA mutation.

M. Rio, MD, PhD, A.S. Lebre, PhD, P. de Lonlay, MD, PhD, V. Valayannopoulos, PhD, I. Desguerre, MD, PhD, J.-L. Dufier, MD, D. Grévent, $M D, M$. Zilbovicius, $M D, P h D, C$. Tréguier, $M D, F$. Brunelle, $M D$, PhD, C. de Baracé, MD, J. Kaplan, MD, PhD, M.A. Espinase-Berrod, MD, C. Sainte-Rose, MD, S. Puget, MD, A. Rotig, PhD, A. Munnich, MD, PhD, N. Boddaert, MD, PhD, Paris, Rennes, Saint Brieuc, France Disclosure: The authors report no disclosures.

Address correspondence and reprint requests to Dr. Marlène Rio, Département de Génétique, Tour Lavoisier $2^{\grave{e} e ́ t a g e, ~ H o ̂ p i t a l ~ N e c k e r-~}$ Enfants Malades, 149 rue de Sèvres, 75015 Paris, France; marlene.rio@nck.aphp.fr

1. Shanske S, Coku J, Lu J, et al. The G13513A mutation in the ND5 gene of mitochondrial DNA as a common cause of MELAS or Leigh syndrome: evidence from 12 cases. Arch Neurol 2008;65:368-372.

2. Lim BC, Park JD, Hwang H, et al. Mutations in ND subunits of complex I are an important genetic cause of childhood mitochondrial encephalopathies. J Child Neurol 2009;24:828-832. 


\section{Neurology}

\section{Mitochondrial ND5 mutations mimicking brainstem tectal glioma}

M. Rio, A.S. Lebre, P. de Lonlay, et al.

Neurology 2010;75;93

DOI 10.1212/WNL.0b013e3181e6214a

\section{This information is current as of July 5, 2010}

\section{Updated Information \& Services}

\section{References}

Citations

Subspecialty Collections

Permissions \& Licensing

Reprints including high resolution figures, can be found at: http://n.neurology.org/content/75/1/93.full

This article cites 2 articles, 0 of which you can access for free at: http://n.neurology.org/content/75/1/93.full\#ref-list-1

This article has been cited by 1 HighWire-hosted articles: http://n.neurology.org/content/75/1/93.full\#\#otherarticles

This article, along with others on similar topics, appears in the following collection(s):

Mitochondrial disorders

http://n.neurology.org/cgi/collection/mitochondrial_disorders Mitochondrial disorders; see Genetics/Mitochondrial disorders http://n.neurology.org/cgi/collection/mitochondrial_disorders_see_gene tics-mitochondrial_disorders

MRI

http://n.neurology.org/cgi/collection/mri

Optic nerve

http://n.neurology.org/cgi/collection/optic_nerve

Visual loss

http://n.neurology.org/cgi/collection/visual_loss

Information about reproducing this article in parts (figures,tables) or in its entirety can be found online at:

http://www.neurology.org/about/about_the_journal\#permissions

Information about ordering reprints can be found online:

http://n.neurology.org/subscribers/advertise

Neurology ${ }^{\circledR}$ is the official journal of the American Academy of Neurology. Published continuously since 1951, it is now a weekly with 48 issues per year. Copyright . All rights reserved. Print ISSN: 0028-3878. Online ISSN: 1526-632X.

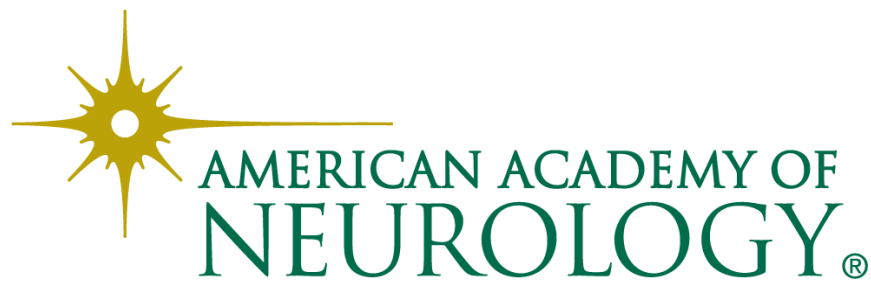

